\title{
Tritylation of Alcohols under Mild Conditions without Using Silver Salts
}

\author{
Shahien Shahsavari, ${ }^{\ddagger}$ Jinsen Chen, ${ }^{\ddagger}$ Travis Wigstrom, James Gooding, Alexander Gauronskas and Shiyue \\ Fang*
}

Department of Chemistry, Michigan Technological University, 1400 Townsend Drive, Houghton, MI 49931, USA

\section{ARTICLE INFO}

\section{ABSTRACT}

\section{Article history:}

Received

Received in revised form

Accepted

Available online

Keywords:

Protecting groups

Alcohols

Nucleosides

Tritylation

Trifluoroacetic anhydride
Secondary alcohols were conveniently tritylated under mild conditions within a short running time with tritylium trifluoroacetate generated in situ from trityl alcohols and trifluoroacetic anhydride. No expensive silver salts were needed for the reactions. Four secondary alcohols were tritylated with both mono- and dimethoxy trityl alcohols giving good to excellent isolated yields. The reaction was also tested on four nucleoside derivatives that have primary alcohols. Satisfactory results were also obtained.

\section{Introduction}

The triphenylmethyl (trityl) groups including the 4monomethoxy- and 4,4'-dimethoxytrityl groups have been widely used for protecting alcohols in organic synthesis including synthesis of DNA, RNA and peptides. These protecting groups are stable under basic conditions, and can be readily removed with a mild acid. The most widely used reagents for introducing them onto an alcohol are trityl chlorides. The conditions are stirring the substrate alcohol with trityl chloride in pyridine, which also serves as the base to neutralize the side product hydrogen chloride, at room temperature. ${ }^{1}$ The method works well for unhindered primary alcohols. However, when it is used to protect the more hindered secondary alcohols, the reactions are usually slow and the yields are mostly poor. The most efficient and widely used method to solve the problem in the literature is to use a silver salt such as $\mathrm{AgNO}_{3}$ and $\mathrm{AgO}_{3} \mathrm{SCF}_{3}$ to abstract the chloride of the trityl chloride to form a high concentration trityl cation solution, which speeds up the tritylation reaction. Using this method, tritylation of secondary alcohols can usually be achieved at ambient temperature within several hours. ${ }^{2}$ In some cases higher temperature and longer reaction time were used, which were probably needed to achieve satisfactory yields. ${ }^{3}$ Besides using silver salts, DMAP had been used to catalyze the reaction. Although DMAP is more available than silver salts,

\footnotetext{
* Corresponding author. Tel.: +1 906487 2023; fax: +1 9064872061.

E-mail address: shifang@mtu.edu (S. Fang).

$\$$ These authors contributed equally.
}

longer reaction time and higher temperature were mostly used for secondary alcohols. ${ }^{3 a, 4}$ Other strategies to facilitate tritylation of secondary alcohols include using a stronger base such as DBU and $\mathrm{NaH}$ to deprotonated the alcohol. ${ }^{5}$ However, $\mathrm{NaH}$ may have substrate compatibility issues, and when DBU was used, long reaction time was required.

Recently, we needed to form a trityl ether linkage between a complex trityl alcohol derivative and a hindered secondary alcohol. We first converted the trityl moiety to a trityl chloride with acetyl chloride under reported conditions. ${ }^{6}$ We then screened all the known conditions discussed above for the formation of trityl ethers. However, none of them including the most powerful one involving $\mathrm{AgNO}_{3}$ gave satisfactory results. With many trials under different unprecedented conditions, we finally succeeded by treating the trityl alcohol with trifluoroacetic anhydride followed by reacting the intermediate carbocation with the secondary alcohol. These results will be reported in due course. Owing to several very significant advantages of the new tritylation method over reported ones, we decided to carry out the reaction condition optimization and substrate scope studies. We did not intend to limit the studies to secondary alcohols. Instead, we also included primary alcohols. The reason is that besides its high efficiency for the tritylation of more hindered secondary alcohols without using silver salts, the method has other advantages. For example, the method uses trityl alcohol instead of trityl chloride as the reagent. Trityl alcohol is stable while trityl chloride is moisture sensitive. In addition, trityl chlorides are mostly made from trityl alcohols, and therefore the latter could be less expensive. Based on these considerations, our studies included not only secondary alcohols but also primary ones. 


\section{Table 1}

Optimization of reaction conditions for tritylation of alcohols using trityl alcohol and trifluoroacetic anhydride as the reagents ${ }^{\mathrm{a}}$
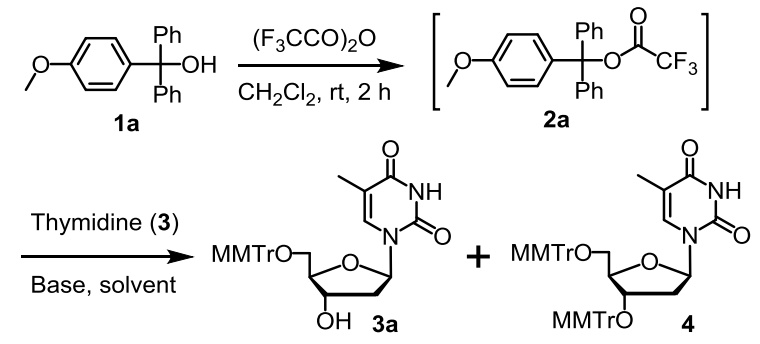

\begin{tabular}{lllll}
\hline Entry & Solvent & Base & Yield (3a) $)^{\mathrm{b}}$ & Yield (4) \\
\hline 1 & $\mathrm{CH}_{2} \mathrm{Cl}_{2}$ & $2,6-$ Lutidine & $14 \%$ & $36 \%^{\mathrm{b}}$ \\
2 & $\underline{\mathbf{T H F}}$ & $\underline{\mathbf{2 , 6}-\text { Lutidine }}$ & $\underline{\mathbf{8 2 \%}}$ & $<5 \%^{\mathrm{c}}$ \\
3 & $\mathrm{DMF}$ & $2,6-$ Lutidine & $46 \%$ & $<5 \%^{\mathrm{c}}$ \\
4 & $\mathrm{CH}_{3} \mathrm{CN}$ & $2,6-$-Lutidine & $47 \%$ & $5 \%^{\mathrm{b}}$ \\
5 & $\mathrm{THF}$ & Pyridine & $52 \%$ & $<5 \%^{\mathrm{c}}$ \\
6 & $\underline{\mathbf{T H F}}$ & $\underline{\text { DIEA }}$ & $\underline{\mathbf{9 1 \%}}$ & $<5 \%^{\mathrm{c}}$ \\
7 & $\mathrm{THF}$ & DBU & $79 \%$ & $<5 \%^{\mathrm{c}}$ \\
\hline
\end{tabular}

${ }^{\mathrm{a}}$ Reaction conditions: Trityl alcohol 1a (1.2 equiv.), $\left(\mathrm{F}_{3} \mathrm{CCO}\right)_{2} \mathrm{O}(3.0$ equiv.), $\mathrm{CH}_{2} \mathrm{Cl}_{2}, \mathrm{rt}, 2 \mathrm{~h}$, evaporation to give $\mathbf{2 a}$; then thymidine (1 equiv.), base ( 2 equiv.), solvent, $0{ }^{\circ} \mathrm{C}$ to $\mathrm{rt}, 2 \mathrm{~h}$. ${ }^{\mathrm{b}}$ Isolated yields based on thymidine. ${ }^{\mathrm{c}}$ Estimated yield based on TLC. MMTr, monomethoxytrityl. DBU, 1,8-diazabicyclo[5.4.0]undec-7-ene.

\section{Results and Discussion}

For optimization of reaction conditions, we chose monomethoxy trityl alcohol $\mathbf{1 a}$ as the tritylation agent and thymidine (3) as the alcohol substrate. Our plan was to screen the best conditions for selective tritylation of a primary alcohol in the presence of a secondary one, then test the conditions on secondary alcohols. The results are summarized in Table 1. Trityl alcohol 1a (1.2 equivalents) was treated with trifluoroacetic anhydride (3 equivalents) in dichloromethane under an argon atmosphere, which gave the presumptive intermediate 2a. The volatiles including dichloromethane, remaining trifluoroacetic anhydride (boiling point, $40^{\circ} \mathrm{C}$ ) and trifluoroacetic acid (boiling point, $72{ }^{\circ} \mathrm{C}$ ) were simply removed on a rotary evaporator under reduced pressure provided by a water aspirator. Even though small amount of water vapor from the aspirator may potentially diffuse to the flask to hydrolyze $\mathbf{2 a}$, we did not pay any particular attention on this issue (e.g. attaching a Drierite or sodium hydroxide drying tube between the evaporator and aspirator) except for stopping the process timely after the evaporation was complete. The flask containing 2a was reattached to an argon atmosphere and flushed with argon. We then carried out studies on optimization of the reaction conditions by screening for the best solvents and bases. For identifying the most suitable solvents, we used the hindered non-coordinating base 2,6-lutidine (2 equivalents) in all cases. The substrate thymidine (1 equivalent), 2,6-lutidine ( 2 equivalents), and the solvent to be screened were charged to a round-bottomed flask and cooled to 0 ${ }^{\circ} \mathrm{C}$. To the flask containing $\mathbf{2 a}$ was added the same solvent. The solution of $\mathbf{2 a}$ was added to the substrate flask, and the mixture was stirred while warming to room temperature within a preset time of 2 hours. As shown in Table 1, dichloromethane was found to be more favorable to di-tritylation over mono-tritylation of thymine giving $\mathbf{4}$ as the major product (entry 1). The overall yield was however not high, which may be a result of the low solubility of thymidine in the solvent. Under the same conditions, we screened three more polar solvents - THF, DMF and acetonitrile, in which thymidine is more soluble (entries 2-4). THF gave the best results. Importantly, the reaction is highly selective favoring primary over secondary alcohol giving the mono-tritylated product 3a in $82 \%$ yield. Traces of di-tritylated product 4 could be observed on TLC, but isolation was difficult and not pursued. With DMF and acetonitrile as solvents, the reaction also favored mono-tritylation, but the overall yields were lower. Because THF is a widely used organic solvent in typical organic labs and a wide range of organic compounds are readily soluble in it, we concluded that THF should be the solvent of choice for next studies.

To select the most suitable base for the reaction, we screened pyridine, 1,8-diazabicyclo[5.4.0]undec-7-ene (DBU) and diisopropylethylamine (DIEA). The more coordinating base pyridine gave significantly lower yield (entry 5 , Table 1 ). The non-coordinating bases DIEA and DBU both gave good results (entries 6-7). In all the three cases, the primary alcohol could be selectively tritylated. Only traces of di-tritylated product (4) could be observed on TLC. Because DIEA gave the highest yield and close to $100 \%$ selectivity for mono-tritylation, and it is more volatile and easier to evaporate, we concluded that DIEA is a better choice than our originally selected 2,6-lutidine although both bases gave excellent results. Therefore, the best conditions for the new tritylation reaction is to generate $\mathbf{2 a}$ with a trityl alcohol and trifluoroacetic anhydride, and react $\mathbf{2 a}$ with an alcohol substrate in THF using DIEA as the base for neutralization of the trifluoroacetic acid side product.

After successful identification of the most suitable conditions for the new tritylation method, we carried out substrate scope studies. We started by testing the optimized conditions on the more challenging secondary alcohols. The results are summarized in Table 2. Because there was no concern of ditritylation as in the case of $\mathbf{3}$, the standard procedure was modified slightly and the intermediate $\mathbf{2 a}$ or $\mathbf{2 b}$ were mixed with the alcohol substrate and base at room temperature instead of 0 ${ }^{\circ} \mathrm{C}$. Substrates 5-8 were all readily tritylated with both monomethoxy- and dimethoxytrityl alcohols. Good to excellent yields were obtained in all the cases (entries 1-4). It is remarkable that in the literature only low yields could be obtained when the alcohol 6 was tritylated with mono- and dimethoxytrityl tetrafluoroborates (6a 27\%, 6b 32\%). ${ }^{7}$ Compounds 7a-b and 8ab were also successfully prepared in high yields using trityl chlorides as reagent in the literature. However, microwave irradiation had been used to facilitate the reactions. ${ }^{8}$ Compound $\mathbf{8 b}$ was also made using benzyl dimethoxytrityl ether as the reagent in good yield, but expensive reagents including diethyl azodicarboxylate and $\mathrm{Ce}(\mathrm{OTf})_{4}$ had to be used as activators. ${ }^{9}$ Compared to those reported methods for tritylation of secondary alcohols, our method is much simpler and uses much less expensive reagents.

Because trityl groups have been widely used in solid phase oligonucleotide synthesis for protecting the 5'-OH group of nucleoside monomers, and nucleosides are more polar than typical organic compounds, we decided to test the method for tritylation of the primary alcohol of the nucleoside substrates 9 11 and 3. As shown in Table 2, all of them were successfully 
Table 2

Substrate scope studies on tritylation of alcohol using trityl alcohol and trifluoroacetic anhydride ${ }^{\mathrm{a}}$

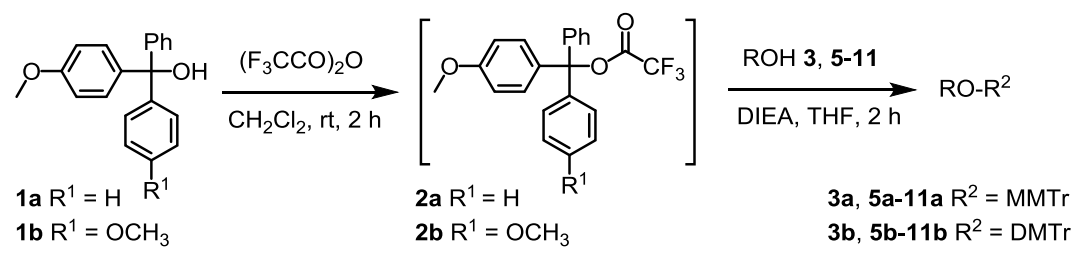

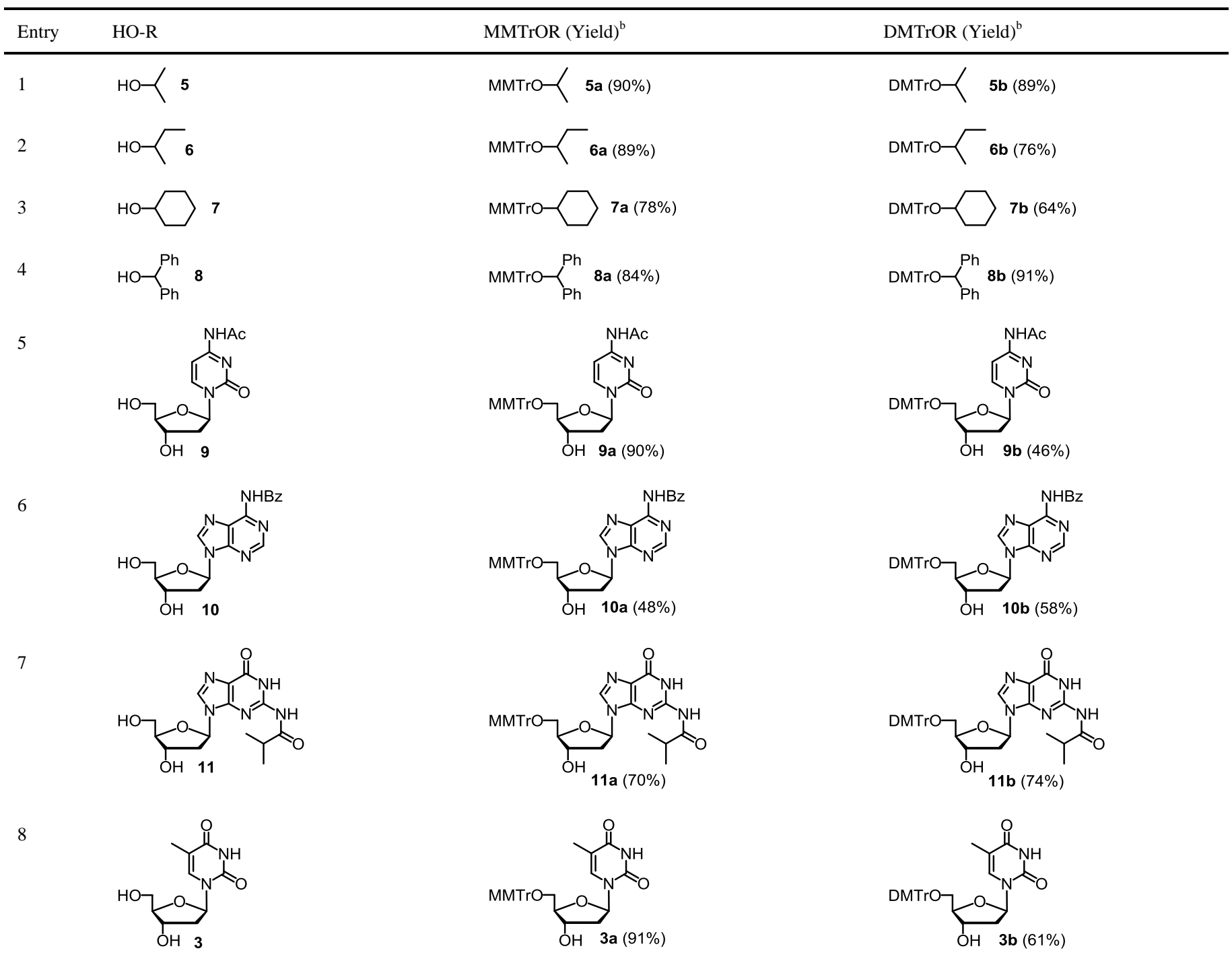

${ }^{a}$ Reaction conditions: Trityl alcohol 1a-b (1.2 equiv.), $\left(\mathrm{F}_{3} \mathrm{CCO}\right)_{2} \mathrm{O}$ (3.0 equiv.), $\mathrm{CH}_{2} \mathrm{Cl}_{2}, \mathrm{rt}, 2 \mathrm{~h}$, evaporation to give 2a-b; then ROH (1 equiv.), DIEA (2 equiv.), THF, rt (5-8) or $0^{\circ} \mathrm{C}$ to rt $(\mathbf{3 , 9 - 1 1}), 2 \mathrm{~h}$. ${ }^{\mathrm{b}}$ Isolated yields based on alcohol. MMTr, monomethoxytrityl. DMTr, dimethoxytrityl.

tritylated using our simple and convenient standard procedure (entries 5-8). In several cases, the yields were moderate, but we believe they can be improved by more careful manipulation during workup and flash column chromatography.

The much higher reactivity of trityl trifluoroacetates $\mathbf{2 a - b}$ than the commonly used trityl chlorides 13a-b toward secondary alcohols can be rationalized using equations (1)-(2). For the tritylation reaction to occur, $\mathbf{2} \mathbf{a}-\mathbf{b}$ and $\mathbf{1 3 a}-\mathbf{b}$ have to be dissociated to the cations $\mathbf{1 2} \mathbf{a}-\mathbf{b}$ and $\mathbf{1 4 a}-\mathbf{b}$, respectively. It is reasonable to believe that trifluoroacetate is less coordinative than chloride because its negative charge is delocalized to two oxygen atoms. Therefore, equation (1) is more favored to the cation side than equation (2), giving a higher concentration of the cations, which render the follow-up trityl ether formation reaction faster. The observation of much deeper red color of $\mathbf{2} \mathbf{b}$ than $\mathbf{1 3 b}$ in dichloromethane at the same molar concentration is well in line with the hypothesis. The selectivity of mono- and ditritylation of thymidine (3) in different solvents can also be explained by equations (1)-(2). As shown in Table 1, ditritylation product $\mathbf{4}$ is favored over mono-tritylated product $\mathbf{3 a}$ when the non-polar dichloromethane was used as solvent (entry 1). In contrast, when the more polar solvents THF, DMF and acetonitrile were used, the mono-tritylated product 3a was 


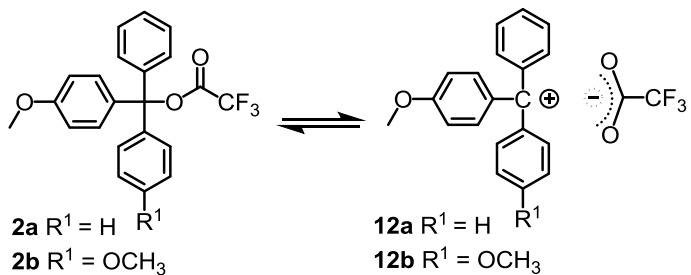

b $\mathrm{R}^{1}=\mathrm{OCH}_{3}$

12b R $\mathrm{R}^{1}=\mathrm{OCH}_{3}$

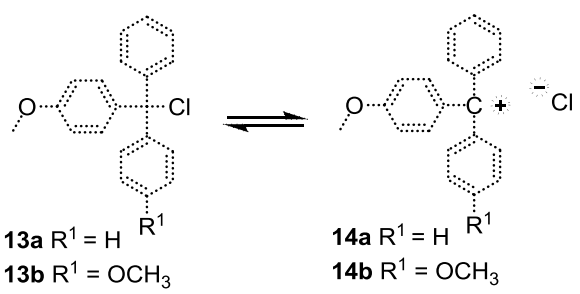

formed almost exclusively. The rationale is that the polar solvents coordinate with the cation 12a and reduce its reactivity, and therefore increase selectivity. The overall higher yield with THF as a solvent over others (entries 1-4) is likely a result of combined effects of substrate solubility in the solvents and the degree to which the solvents coordinate to the cation. As to the effect of different bases on the yields (entries 2 and 5-7, Table 1), the more coordinating base pyridine gave much lower yield. The non-coordinating ones including 2,6-lutidine, DIEA and DBU gave much higher yields. The lower yield with pyridine is a result of the lower reactivity of the cation 12a caused by coordination to the base.

There are several reasons for trifluoroacetic anhydride to stand out as an ideal reagent for activating the trityl alcohols 1a-b from several other potential candidates such as trifluoroacetyl chloride, $p$-toluenesulfonyl chloride, trifluoromethanesulfonyl chloride, acetic anhydride, $p$-toluenesulfonic anhydride, methanesulfonic anhydride, and trifluoromethanesulfonyl anhydride. Among them, all the chlorides will give a trityl chloride intermediate such as 13a-b, which have lower reactivity. Compared to all the anhydrides, trifluoroacetic anhydride is relatively stable and easy to handle while has high reactivity to form the intermediates such as 2a-b. Its boiling point is low $\left(40^{\circ} \mathrm{C}\right)$, which allows to use excess amount for activation of the trityl alcohols to ensure complete reaction because the remaining reagent can be easily evaporated. The side product trifluoroacetic acid also has a low boiling point $\left(72{ }^{\circ} \mathrm{C}\right)$, which allows easy removal too. As stated in the introduction section, the new tritylation method has several significant advantages over known methods. It is highly reactive toward secondary alcohols, and does not require expensive activators such as $\mathrm{AgNO}_{3}$. Compared with using trityl chlorides as the reagent, there is no concern of hydrolysis since trityl alcohol is stable and trifluoroacetic anhydride can be used in excess. Furthermore, trityl alcohols are potentially less expensive than the widely used trityl chlorides since the common way to make the latter is chlorination of the former. ${ }^{10}$ Finally the new method provides an attractive alternative approach for the formation of trityl ether linkage from sensitive and complex trityl alcohol and alcohol substrates, where known methods do not work well or do not work at all.

\section{Conclusion}

In summary, we have developed a new method for the tritylation of alcohols. Both primary and secondary alcohols were found to be good substrates for the reaction. Compared to known tritylation methods, the most significant advantage of the new method is the capability to tritylate secondary alcohols under mild conditions in a short time without using expensive silver salts. Several other advantages are also significant. The reagent used in the method is trityl alcohol, which is more stable and potentially less expensive than the more commonly used trityl chloride. We expect that the method find wide applications for the protection of alcohols in organic synthesis. More importantly, the method provides a potential solution for the formation of trityl ether linkages between complex and sensitive substrates where known methods do not work.

\section{Acknowledgments}

Financial support from NIH (R15GM109288), NSF (CHE1111192 and CH0647129) and MTU SURF (T.W.); the assistance from Mr. D.W. Seppala (electronics) and Mr. J.L. Lutz (NMR); NSF equipment grants (CHE-1048655 and CHE9512455); and MSU Mass Facility (HRMS) are gratefully acknowledged.

\section{Supplementary Material}

Supplementary data associated with this article can be found, in the online version, at

\section{References}

1. (a) Ozols, K.; Cirule, D.; Novosjolova, I.; Stepanovs, D.; Liepinsh, E.; Bizdena, E.; Turks, M. Tetrahedron Lett. 2016, 57, 1174-1178; (b) Saito, Y.; Suzuki, A.; Yamauchi, T.; Saito, I. Tetrahedron Lett. 2015, 56, 3034-3038; (c) Dang, Q.; Zhang, Z. B.; He, S. S.; Liu, Y. H.; Chen, T. Q.; Bogen, S.; Girijavallabhan, V.; Olsen, D. B.; Meinke, P. T. Tetrahedron Lett. 2014, 55, 4407-4409; (d) Hernandez, O.; Chaudhary, S. K.; Cox, R. H.; Porter, J. Tetrahedron Lett. 1981, 22, 1491-1494; (e) Seliger, H. Current Protocols in Nucleic Acid Chemistry 2000, Unit 2.3.1-2.3.34.

2. (a) Wang, G. Y.; Deval, J.; Hong, J.; Dyatkina, N.; Prhavc, M.; Taylor, J.; Fung, A.; Jin, Z. N.; Stevens, S. K.; Serebryany, V.; Liu, J. W.; Zhang, Q. L.; Tam, Y. E.; Chanda, S. M.; Smith, D. B.; Symons, J. A.; Blatt, L. M.; Beigelman, L. J. Med. Chem. 2015, 58, 1862-1878; (b) Katolik, A.; Johnsson, R.; Montemayor, E.; Lackey, J. G.; Hart, P. J.; Damha, M. J. J. Org. Chem. 2014, 79, 963-975; (c) Simeone, L.; Irace, C.; Di Pascale, A.; Ciccarelli, D.; D'Errico, G.; Montesarchio, D. Eur. J. Med. Chem. 2012, 57, 429-440; (d) Gomes, C. P.; Metz, A.; Bats, J. W.; Gohlke, H.; Gobel, M. W. Eur. J. Org. Chem. 2012, 3270-3277; (e) Dias, L. C.; de Lucca, E. C.; Ferreira, M. A. B.; Garcia, D. C.; Tormena, C. F. J. Org. Chem. 2012, 77, 1765-1788; (f) Pav, O.; Panova, N.; Snasel, J.; Zbornikova, E.; Rosenberg, I. Bioorg. Med. Chem. Lett. 2012, 22, 181-185; (g) Pav, O.; Kosiova, I.; Barvik, I.; Pohl, R.; Budesinsky, M.; Rosenberg, I. Org. Biomol. Chem. 2011, 9, 6120-6126; (h) James, D.; Escudier, J. M.; Amigues, E.; Schulz, J.; Vitry, C.; Bordenave, T.; Szlosek-Pinaud, M.; Fouquet, E. Tetrahedron Lett. 2010, 51, 1230-1232.

3. (a) Sau, S. P.; Fahmi, N. E.; Liao, J. Y.; Bala, S.; Chaput, J. C. J. Org. Chem. 2016, 81, 2302-2307; (b) Kel'in, A. V.; Zlatev, I.; Harp, J.; Jayaraman, M.; Bisbe, A.; O'Shea, J.; Taneja, N.; Manoharan, R. M.; Khan, S.; Charisse, K.; Maier, M. A.; Egli, M.; Rajeev, K. G.; Manoharan, M. J. Org. Chem. 2016, 81, 2261-2279; (c) Filichev, V. V.; Pedersen, E. B. Bioorg. Med. Chem. Lett. 2004, 14, 581-584; (d) Oka, N.; Sanghvi, Y. S.; Theodorakis, E. A. Bioorg. Med. Chem. Lett. 2004, 14, 3241-3244.

4. (a) Lain, L.; Lonnberg, H.; Lonnberg, T. Org. Biomol. Chem. 2015, 13, 4737-4742; (b) Sciebura, J.; Janiak, A.; Stasiowska, A.; Grajewski, J.; Gawronska, K.; Rychlewska, U.; Gawronski, J. ChemPhysChem 2014, 15, 1653-1659; (c) Fomich, M. A.; Kvach, M. V.; Navakouski, M. J.; Weise, C.; Baranovsky, A. V.; Korshun, V. A.; Shmanai, V. V. Org. Lett. 2014, 16, 4590-4593.

5. (a) Ren, K.; Zhao, M. M.; Hu, B.; Lu, B.; Xie, X. M.; RatovelomananaVidal, V.; Zhang, Z. G. J. Org. Chem. 2015, 80, 12572-12579; (b) Jereb, M.; Vrazic, D. Org. Biomol. Chem. 2013, 11, 1978-1999; (c) Schwizer, D.; Patton, J. T.; Cutting, B.; Smiesko, M.; Wagner, B.; Kato, A.; Weckerle, C.; Binder, F. P. C.; Rabbani, S.; Schwardt, O.; Magnani, J. L.; Ernst, B. Chem. Eur. J. 2012, 18, 1342-1351; (d) Joosten, A.; 
Lambert, E.; Vasse, J. L.; Szymoniak, J. Org. Lett. 2010, 12, 51285131. (e) Colinmessager, S.; Girard, J. P.; Rossi, J. C. Tetrahedron Lett. 1992, 33, 2689-2692.

6. (a) Pearson, W. H.; Berry, D. A.; Stoy, P.; Jung, K. Y.; Sercel, A. D. J. Org. Chem. 2005, 70, 7114-7122; (b) Pokharel, D.; Fang, S. Y. Green Chem. 2016, 18, 1125-1136; (c) Beller, C.; Bannwarth, W. Helv. Chim. Acta 2005, 88, 171-179.

7. Bleasdale, C.; Ellwood, S. B.; Golding, B. T. J. Chem. Soc. Perk. Trans. 1 1990, 803-805.

8. Zekri, N.; Alamdari, R. F.; Khalafi-Nezhad, A. Bull. Chem. Soc. Ethiopia 2010, 24, 299-304.

9. Zekri, N.; Alamdari, R. F. Can. J. Chem. 2010, 88, 563-568.

10. Bachmann, W. E.; Hauser, C. R.; Hudson, B. E. J. Org. Synth. 1943, 23, 100. 


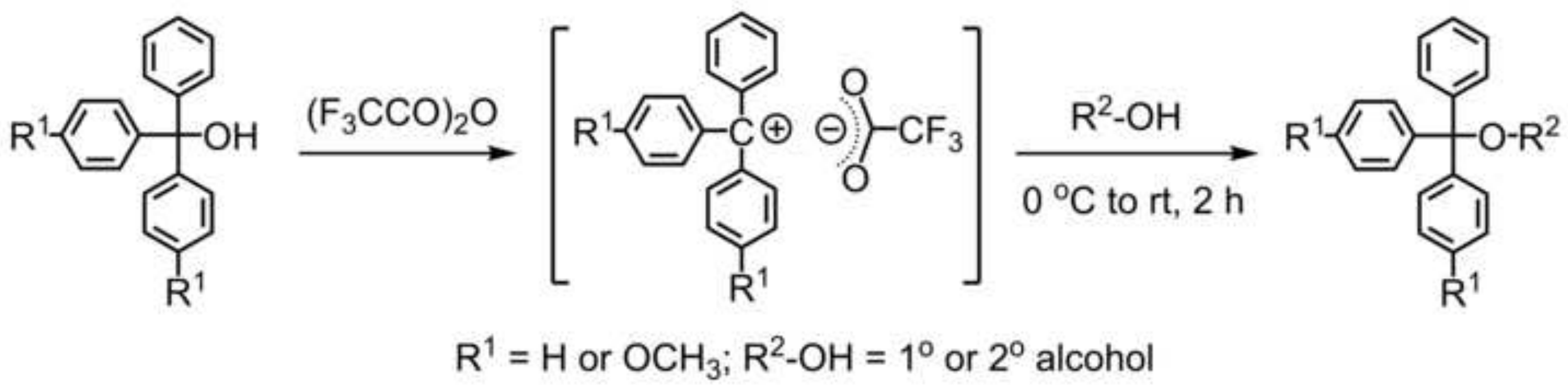

$$
\mathrm{R}^{1}=\mathrm{H} \text { or } \mathrm{OCH}_{3} ; \mathrm{R}^{2}-\mathrm{OH}=1^{\circ} \text { or } 2^{\circ} \text { alcohol }
$$

